This item was submitted to Loughborough's Research Repository by the author.

Items in Figshare are protected by copyright, with all rights reserved, unless otherwise indicated.

\title{
An holistic view of UK military capability development
}

PLEASE CITE THE PUBLISHED VERSION

http://dx.doi.org/10.1080/14751790902749900

PUBLISHER

(C) Routledge (Taylor and Francis Group)

VERSION

AM (Accepted Manuscript)

LICENCE

CC BY-NC-ND 4.0

REPOSITORY RECORD

Yue, Yi, and Michael Henshaw. 2019. "An Holistic View of UK Military Capability Development". figshare. https://hdl.handle.net/2134/4392. 
This item was submitted to Loughborough's Institutional Repository (https://dspace.lboro.ac.uk/) by the author and is made available under the following Creative Commons Licence conditions.

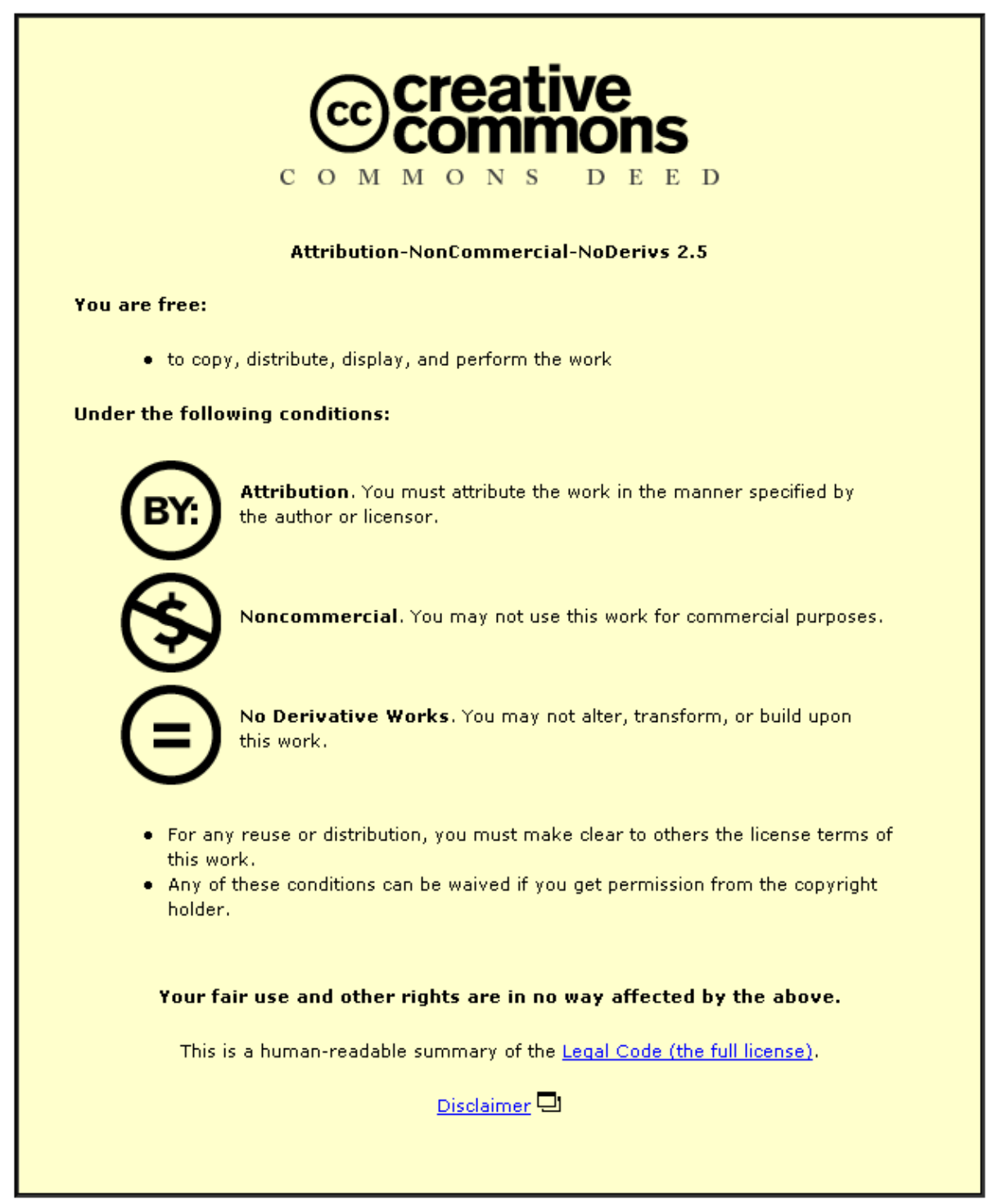

For the full text of this licence, please go to: http://creativecommons.org/licenses/by-nc-nd/2.5/ 


\section{An Holistic View of UK Military Capability Development* Yi Yue ${ }^{\dagger}$ \\ Defence Science and Technology Organisation, Australia \\ Michael Henshaw ${ }^{\ddagger}$ \\ Loughborough University, UK}

\section{Abstract}

Through Life Capability Management (TLCM) is the dominant theme of proposed changes to UK defence acquisition, but progress has been hindered by a lack of agreed interpretations for key concepts. This paper provides some clarity for Capability, Network Enabled Capability (NEC), TLCM, and Affordability and notes, in particular, the fractal nature of capability.

Through stakeholder analysis and concept maps, we identify some of the major challenges associated with TLCM. These include affordability (which is the motivation for TLCM but may also be its stumbling block); the increased priority of agility, adaptability, and flexibility in capability planning; and the need for appropriate TLCM metrics. The lack of an explicit learning mechanism within the capability planning process is also a major deficiency, because TLCM relies on effective knowledge management.

The changing role of industry is considered and the need for an holistic view of capability is emphasised.

\section{Introduction}

In the last few years, several significant policy documents have been published by the UK Ministry of Defence (MoD) that propose radical changes in approach to acquisition and management of defence capability. These include the Defence Industrial Strategy ${ }^{1}$ and Network Enabled Capability ${ }^{2}$. Following on from these, the Enabling Acquisition Change Report $^{3}$ sets out specific recommendations for responses required from the community that plans and develops military capabilities. The key theme is the implementation of Through Life Capability Management (we shall use the acronym TLCM hereafter), which puts a premium on ensuring that: ....military capability is built from the most cost-effective mix of components, and is both affordable to operate through life and readily adaptable ${ }^{3}$.

Because of the novelty of TLCM, there exists much confusion and numerous interpretations of the concepts and processes. This paper provides an holistic view of UK military capability development by articulating a detailed understanding of what TLCM means for defence capability planning, development, and delivery. It will also set the scene for, and provide an appreciation of, the wider context for future TLCM

\footnotetext{
* The views expressed in the document are those of the authors only and do not represent the views of the authors' affiliated organisations.

† Recently on secondment to the UK MOD Defence Science and Technology Laboratory.

‡ Corresponding author: Systems Engineering Innovation Centre, Holywell Park, Loughborough University, LE11 3TU, UK. M.j.d.henshaw@lboro.ac.uk
} 
related researches. We first explore the meanings of some key concepts, and then identify stakeholders and suggest a system boundary. We then describe the conceptual TLCM process and suggest responsibilities among the stakeholders. Finally, we summarise some of the key implications discussed in the paper.

\section{Exploration of the meanings of key concepts}

This section explores four key concepts in the domain: Capability, Network Enabled Capability (NEC), TLCM, and Affordability.

\section{Capability}

According to the Concise Oxford Dictionary, the core meaning of capability is "power or ability to do something" with a subsense of "an undeveloped or unused faculty”. Latency is, thus, an important feature of capability. Another feature becomes apparent when it is considered from a systems perspective. Capability exists in all levels of the hierarchy of a system or components of a system. It is failure to appreciate this feature that has led to misunderstandings when capability is discussed. We may describe capability as being fractal, in the sense of having a 'family resemblance' at all the various levels, but without being precisely similar at all those levels ${ }^{4}$. Strictly, the term fractal implies possession of the same statistical characteristics at all levels; but in this case we mean to imply similar characteristics. This fractal nature of capability implies that capability is only a meaningful concept when it is specified about whose, to do what, and under what circumstances. That is to say firstly that capability is context dependent, but also that the context description contains information about the level at which capability is being considered. For instance, a single UAV and a net-enabled surveillance capability, that includes many sensor bearing assets, special forces, etc., can both be described as surveillance capability, but the single UAV could also be part of the net-enabled capability. i.e. they are at different levels. Nevertheless, the types of parameters used to describe these capabilities are similar (definition/resolution, endurance, communication links, data formats, etc.). On the other hand, a net-enabled surveillance capability is a specific instantiation of the highest level of surveillance capability - the conceptual level. At this highest level, as discussed later in the paper, life cycle is meaningless; whereas at lower level of the capability hierarchy, e.g. at platform level or for a particular instantiation, life cycles can and do exist. This further illustrates the point that the fractal nature which we assert here really implies family resemblance rather than strict self-similarity, i.e. variation between levels is a norm and not an exception.

In TLCM, the $\mathrm{C}$ specifies military capability, of which the UK MoD definition is: the enduring ability to generate a desired operational outcome or effect, and is relative to the threat, physical environment and the contributions of coalition partners. ${ }^{5}$.

This clearly acknowledges that military capability is context dependent. TLCM requires capability to be managed, over time, by a series of creative activities that synthesise a set of fundamental inputs, or components, which are expressed as lines of development. In the UK there are eight Defence Lines of Development (DLOD): Training, Equipment, Personnel, Infrastructure, Concepts \& Doctrine, Organisation, Information and Logistics (Figure 1a). The desired capability can only be achieved if 
the activities within all eight DLOD are at an appropriately matched level of readiness, or maturity; failure to manage across all eight DLOD can lead to serious deficiencies. For example, failure to deliver Apache Helicopter training to schedule resulted in an additional $£ 6 \mathrm{M}$ of costs because some delivered aircraft had to be stored until trained operators were available $e^{6}$ The DLOD are concerned with operational readiness, i.e. development to a level appropriate for deployment (e.g. training refers to the training of military personnel such that the appropriate people are trained to an appropriate level of preparedness for deployment).

For a number of reasons, industry has an ever expanding role in the TLCM domain, as anticipated by the policy documents referred to above. Therefore, there is another capability of concern, which is industrial capability. Industrial capability is usually described in terms of the five attributes (Figure 1b) of People, Processes, Products, Technology, and Facilities ${ }^{7}$. Some authors add capitalisation to these attributes, but we shall assume appropriate investment for the purposes of this paper.

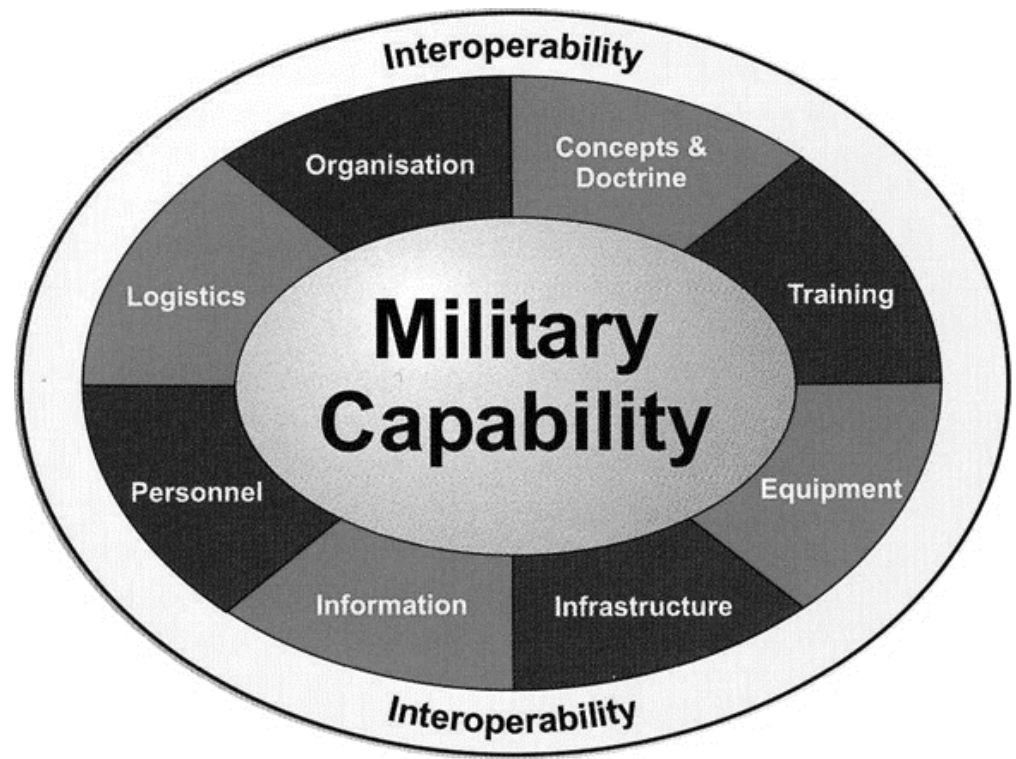

Figure 1a: The Eight UK Defence Lines of Development, from MoD Defence Acquisition Handbook.

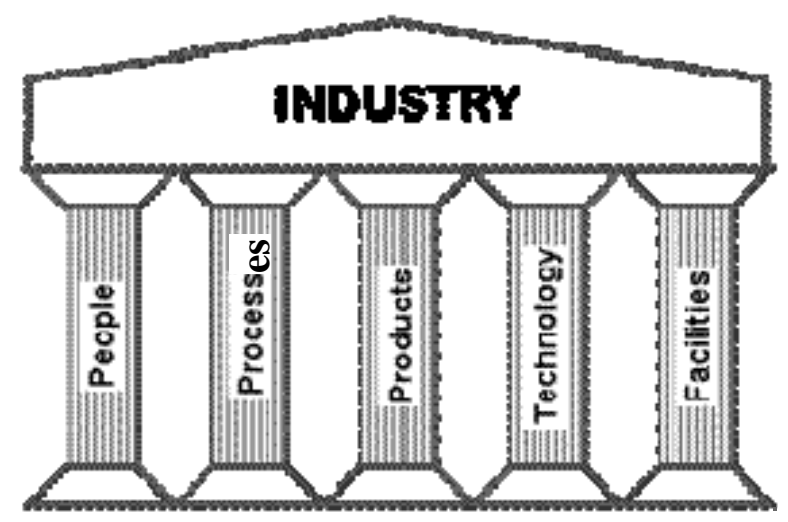

Figure 1b: The five attributes of industrial capability. 
Industrial capability in TLCM context means the ability to supply the right products and services, which may be an integral part of military capability. For example, some industry facilities could form a part of the infrastructure in a military capability. Similarly, industry capability in providing logistic support may be used as part of the logistic DLOD of a military capability. Nevertheless, industry cannot deliver military capability. The realisation of capability, through the integration of attributes across the DLOD at 'point of use' will always be a military task.

From above discussion, it is clear that in the TLCM domain, there are two principal kinds of capability of interest; military and industrial capabilities. They are intertwined but distinct. Hence transforming military capability and transforming industrial capability are two different processes, although they are not independent of each other.

\section{Network Enabled Capability (NEC)}

NEC was introduced as a war fighting concept that breaks away from the traditional stovepiped, hierarchical approach and promotes networking down to the tactical level. It articulates a particular way that the UK military seeks to operate in a networked environment. Unfortunately, misconception has been observed in the military capability development community and the enabling components have sometimes become the dominant consideration. In recent times, it has not been uncommon to hear military capability categorised as either NEC capability or non-NEC capability. To overcome this misconception, a new term: Military Capability Enabled by Networking (MCEN) was introduced by the $\mathrm{MoD}^{8}$. In essence, MCEN conveys the message that the enabling networking capability is not a military capability in its own right; instead it should be a fundamental part of any future military capability and, at the same time, exists across military capabilities. Blair et. al. ${ }^{9}$ have drawn attention to the lack of clarity surrounding the NEC concept and Quintana ${ }^{10}$ has highlighted the concerns in this respect of both Government and industry; further efforts to focus on the capability, and not the network, as the system of interest are to be expected. This is likely to be achieved by defining NEC requirements at the more detailed systems levels.

The promise of NEC brings many desired characteristics of MCEN, such as flexibility, adaptability, agility, reach, lethality, autonomy, etc. These characteristics are the driving requirements for military capability development; hence TLCM and MCEN are inextricably linked and the relationship of the TLCM approach to the MCEN aspirations demands closer attention.

\section{$\underline{T L C M}$}

The official MoD definition of TLCM is:

....an approach to the acquisition and in-service management of military capability in which every aspect of new and existing military capability is planned and managed coherently across all Defence Lines of Development (DLOD) from cradle to grave ${ }^{11}$.

The same document goes on to clarify that:

Since capabilities endure, all capability management is in perpetuity, so the 'through life' is redundant. It is still useful to retain it, as it provides a reminder that decision making needs to take a long-term perspective. ${ }^{11}$ 
This long-term perspective, which includes managing the components of capability on a whole life basis, requires a fundamental shift of mindset in military capability development. Because we are not able to predict the future to any degree of certainty, cost-effective management of what will be future legacy capability components demands that we make adaptability a major driver in the planning and designing stages. Capabilities must be designed to co-evolve with their environment and the evolution must be supported over a very long time. Unfortunately, the approaches required to plan and design adaptable military capability are largely lacking and so this is an urgent area for research; that is to say, it is currently very poorly understood or addressed.

If we were to focus onto any military capability and examine the DLOD, we would see that each DLOD evolves asynchronously with the others, even when hypothetically the capability is kept constant, as illustrated schematically in Figure 2; here the tube represents a military capability notionally kept at a constant level over time and the coloured dots represent DLOD at three different epochs. For any desired capability level, there are multiple feasible ways of DLOD synthesising; and at any particular point of time, the specific content of each DLOD might be different. For example, it might be different equipments to form the same capability. This is, of course, an oversimplification to illustrate the point that there is no unique combination of DLOD to provide a given capability. In fact, military capability is an emergent property arising from the interactions of all the DLOD rather than a simple superposition of them. This adds more complexity for military capability development, since it is almost impossible to fully plan, predict and understand its long-term evolution.

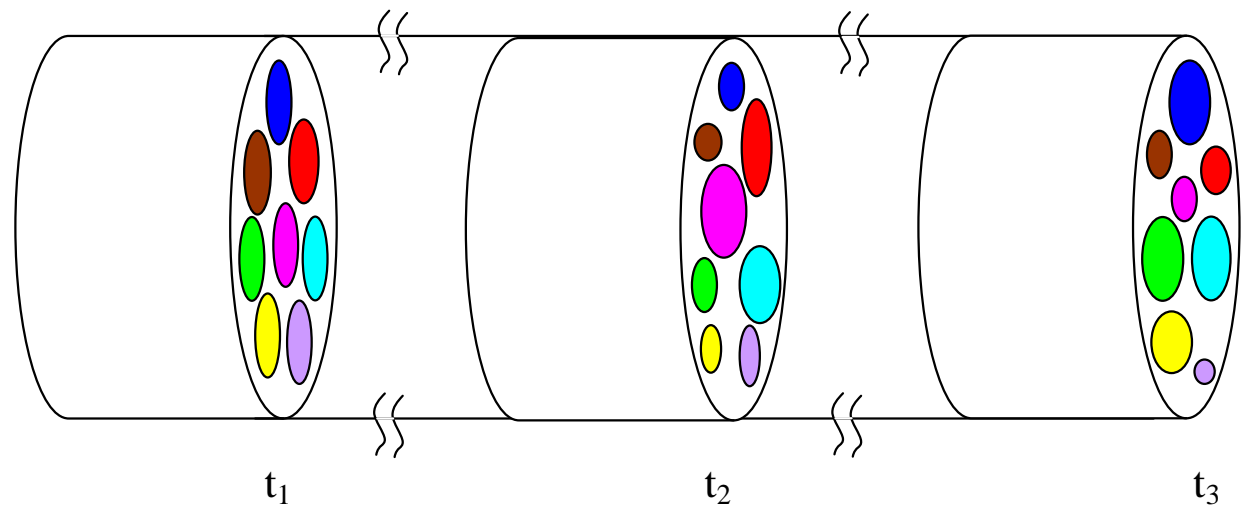

Figure 2. A schematic illustration of asynchronous evolution of DLOD within a military capability.

It is meaningless to talk about the life cycle of a military capability. For some DLOD the concept of life cycle does not apply (i.e. personnel, concepts and doctrine, and information). For those that it does, it is not the DLOD itself, but the components from which it is composed that may have lifecycles, and there may be many at different stages. For instance, a particular capability may include contributions from several components from the equipment DLOD, some of which are about to go out of service and others that have only just been qualified for use. The individual equipments have a lifecycle (concept to disposal), but the overall capability is enduring. Moreover, the relationship between DLOD and military capabilities is many-to-many, i.e. the components of a particular DLOD contributes to more than 
one military capability. So developments of military capabilities and DLOD are intertwined.

As stated above, capability is latent, and hence needs a host. Military capability is vested in Force Elements at Readiness (FE@R). A force element is an building block of a force structure, for instance a ship, or a company of ground forces; readiness implies that those elements that will be able to deploy with planned performance levels within a given notice period ${ }^{12}$. The more capable a FE@R is, the more variety it has to conduct military tasks. The proper combination of right FE@R conducting orchestrated activities enables the generation of desired effects and, in turn, achieves objectives. So when we look through the whole military capability development timeline, it is clear that the fundamental building block that we are dealing with is FE@R, whereas capability is much more abstract. Thus, there are two different time scales and two distinctive innovations. The first may be years, or even decades, before the actual utilisation of the military capability of concern; future requirements are envisaged and the military capability is designed via a conceptual synthesis of all of the DLOD. This design process is often termed Capability Engineering (discussed below), which is generally carried out by military capability planners in consultation with stakeholders. The second is run-time compilation and execution, carried out by front line commanders when, in a much shorter time scale, the military capability is created by specific integration of FE@R. This, actually generated, military capability can be, and usually is, quite different from the original design. It is worth noting that, during the cold war, nations maintained large numbers of FE at comparatively low R, because it was believed there would be warning of an impending war giving time to improve R; now many nations maintain fewer FE, but maintain more at high R.

Figure 3 is a concept map that summarises the key concepts in TLCM and their relationships as discussed above.

\section{Affordability}

Affordability is the motivation at the heart of TLCM, but it provides many and significant challenges. It must be considered by all organisations in the capability enterprise and represents a balancing overall across the enterprise. That is to say that, although it is generally considered to be the affordability as defined by the balance of investment over time by the customer (MoD), it is actually the balance of need and resources over time of all organisations within the enterprise (i.e. customer and suppliers). The basic challenges associated with understanding whole-life costing are very significant and there is currently a lack of appropriate data through which models can be developed ${ }^{13}$. However, the greatest challenges are perhaps those associated with the change in relationship needed between customer and suppliers. Determination of affordability requires a considerable sharing of information about costs, assumptions, objectives, and strategy in a manner that completely changes the nature of competition within the defence market.

This very motivation may well prove to be the stumbling block for the proper realisation of TLCM. 


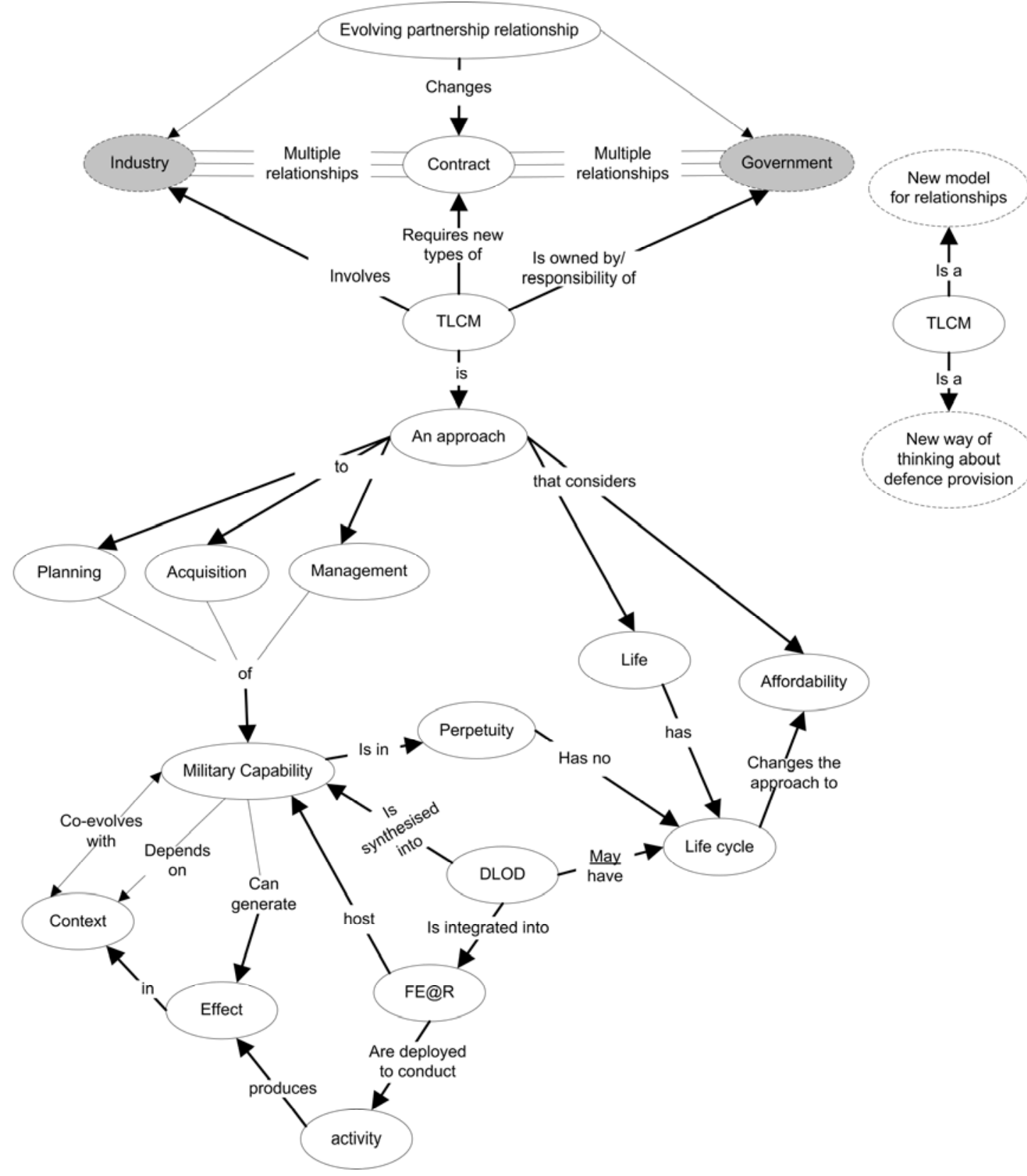

Figure 3. A TLCM concept map

\section{Stakeholder identification and system boundary judgement}

Capability Engineering generally requires consideration of, so-called, Systems of Systems. There is a lack of agreement about what this term actually means ${ }^{14}$, but we conceive it to describe the situation in which a number of independent systems, which are capable of autonomous action and the achievement of whole effects individually, act together in a planned, or unplanned fashion, to achieve other effects that are unachievable by any of the individual systems acting in isolation. The importance of this concept is that traditionally a systems engineer will be able to draw the system boundary for a particular system, but this task becomes considerably more complex and ambiguous for a System of Systems. Both military capability and its acquisition can be considered to be problems in Systems of Systems (though at different levels). 
It is a moot point whether capability engineering means engineering of capabilities, or engineering with capabilities. Using the notion of capability having a fractal, or layered, nature, there is a level at which DLODs are brought together to create FE@R; i.e. engineering of capabilities. Above this there is a level at which capabilities are built by combining FE@Rs, subordinate capabilities, and high level concepts and doctrine; this can be described as engineering with capabilities. Taylor ${ }^{15}$ has described this latter as being more akin to capability-based planning.

Military capability development covers the whole spectrum of planning, designing, acquisition, management and application of military capability. It is a very complex problem and concerns many issues, such as politics, finance, environment, management, research and development, project management, engineering, and human resources. There is a large, diverse range of stakeholders besides the numerous organisations directly involved. These organisations exhibit various behaviours and the stakeholders all have their own objectives, which are not necessarily aligned and may sometimes be conflicting. In this section, we conduct a broad brush stakeholder analysis, and then make a system boundary judgement.

For a first pass at the stakeholder analysis, we consider only stakeholder organisations and indicate for each their overall goals, their TLCM objectives and roles, as shown in Table 1. We then consider the impact these have on other stakeholders. Where the environment (or context) significantly modifies this impact, this is indicated as shown in Figure 4.

Figure 4 shows the stakeholder relationships in military capability development and an explicit system boundary judgement, where secondary and external stakeholders are treated as external environment exerting influence or constraints on the system. This system boundary is represented as a dashed line in the diagram. This is a generic representation and the boundary can tighten or relax according to the capability under consideration. For instance, coalition partners must be included sometimes.

This boundary judgement explicitly includes industry as an integral part of the system. For this to be effective, it will require reconsideration of how risks are distributed, transferred and managed among the components of the system. The mentality of "us" and "them" must be changed and a broader perspective maintained. A further implication of such a wider system boundary is the increased complexity involved in TLCM, together with increases in information and knowledge flows (as predicted by Ashby's Law $^{16}$ ). There is a vastly increased stakeholder group that must be considered and a corresponding multiplication of the data and information that must be managed to achieve the TLCM aims. 


\begin{tabular}{|c|c|c|c|}
\hline Stakeholder & Goal & TLCM Objective & TLCM Role \\
\hline $\begin{array}{l}\text { Electorate, } \\
\text { journalists, etc }\end{array}$ & Many and varied & None & None \\
\hline Government & $\begin{array}{l}\text { Defence of national } \\
\text { interests }\end{array}$ & $\begin{array}{l}\text { Maintain armed } \\
\text { forces at a level } \\
\text { necessary to } \\
\text { achieve national } \\
\text { defence and foreign } \\
\text { policy needs }\end{array}$ & $\begin{array}{l}\text { Govern available } \\
\text { funds over time and } \\
\text { provide political } \\
\text { and ethical } \\
\text { environment for } \\
\text { management of } \\
\text { defence }\end{array}$ \\
\hline $\begin{array}{l}\text { MoD - Capability } \\
\text { Developer }\end{array}$ & $\begin{array}{l}\text { Execute } \\
\text { government policy } \\
\text { with respect to } \\
\text { defence }\end{array}$ & $\begin{array}{l}\text { Manage funds and } \\
\text { integrated } \\
\text { capability over } \\
\text { time }\end{array}$ & $\begin{array}{l}\text { Management and } \\
\text { planning of defence } \\
\text { system (capability) }\end{array}$ \\
\hline MoD - Warfighter & $\begin{array}{l}\text { Prosecute military } \\
\text { objectives in } \\
\text { support of } \\
\text { government policy }\end{array}$ & $\begin{array}{l}\text { Maintain } \\
\text { appropriately } \\
\text { interoperable } \\
\text { systems to support } \\
\text { warfighting role, } \\
\text { and ensure } \\
\text { availability of } \\
\text { resources to } \\
\text { achieve warfighting } \\
\text { objectives }\end{array}$ & $\begin{array}{l}\text { Provide } \\
\text { information to } \\
\text { ensure TL planning } \\
\text { and management of } \\
\text { deployed capability }\end{array}$ \\
\hline $\begin{array}{l}\text { Coalition defence } \\
\text { departments }\end{array}$ & $\begin{array}{l}\text { Own national } \\
\text { objectives }\end{array}$ & $\begin{array}{l}\text { Own national } \\
\text { objectives }\end{array}$ & $\begin{array}{l}\text { Define, comply } \\
\text { with international } \\
\text { standards for } \\
\text { interoperability }\end{array}$ \\
\hline Industry - Prime & $\begin{array}{l}\text { Commercial } \\
\text { success }\end{array}$ & $\begin{array}{l}\text { Achieve } \\
\text { commercial success } \\
\text { through long term } \\
\text { provision, } \\
\text { management, of } \\
\text { capability }\end{array}$ & $\begin{array}{l}\text { Service/product } \\
\text { provider; } \\
\text { integration of lower } \\
\text { level systems into } \\
\text { capability systems }\end{array}$ \\
\hline $\begin{array}{l}\text { Industry - lower } \\
\text { tiers }\end{array}$ & $\begin{array}{l}\text { Commercial } \\
\text { success }\end{array}$ & $\begin{array}{l}\text { Achieve } \\
\text { commercial success } \\
\text { through provision } \\
\text { of services and } \\
\text { products within } \\
\text { supply chain }\end{array}$ & $\begin{array}{l}\text { Suppliers of } \\
\text { products and } \\
\text { services that } \\
\text { support capability }\end{array}$ \\
\hline
\end{tabular}

Table 1 Stakeholder analysis summary 


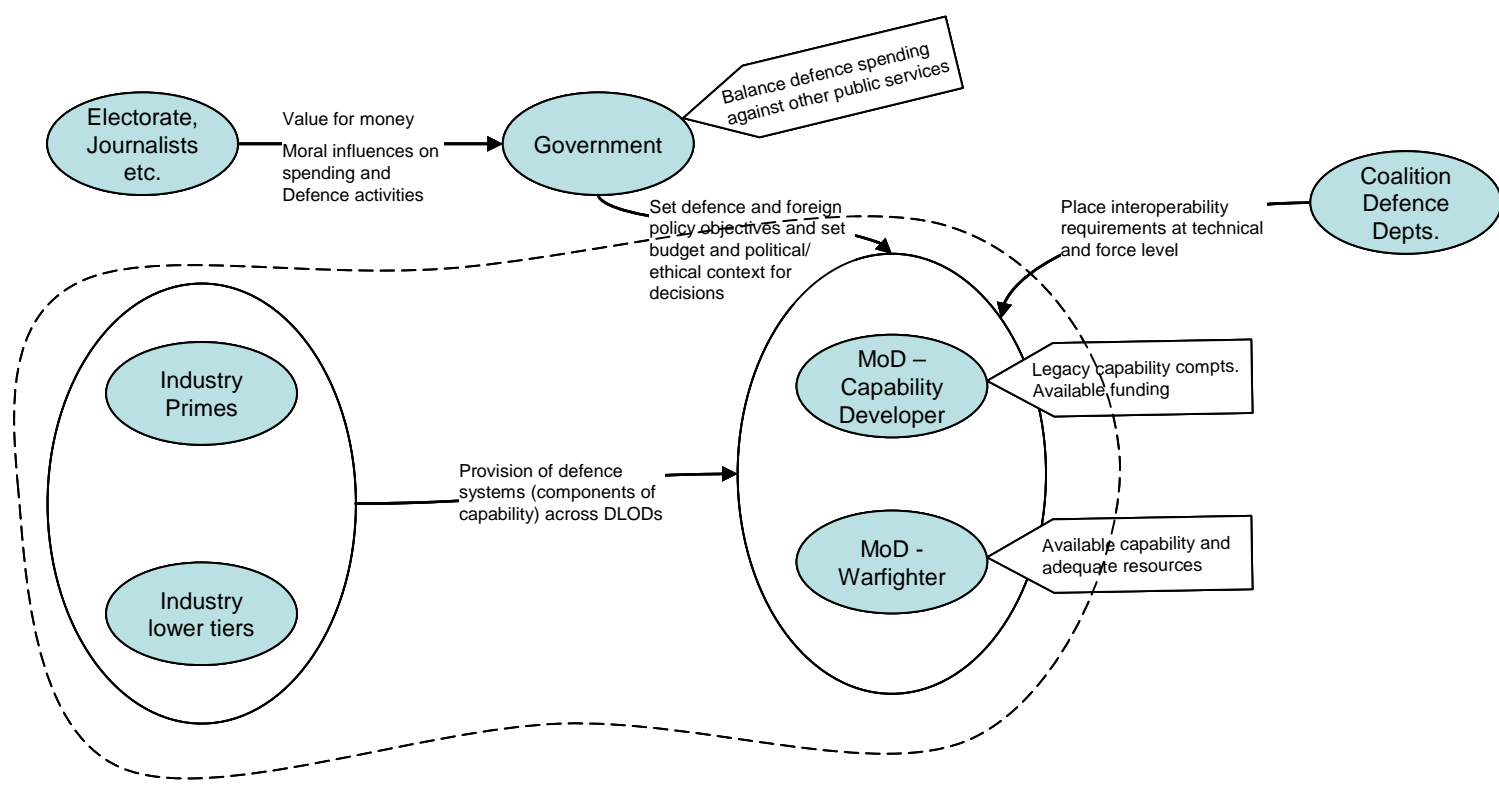

Figure 4 Some significant stakeholder relationships in military capability development

\section{Understanding the UK military capability planning process}

This section discusses the official military capability planning processes in UK MoD. Figure 5 shows a concept map of the broad capability management scheme, which is the front end, i.e. planning stage, of the TLCM. Figure 6 deals with more details of the six step capability planning process as articulated in the Capability Management Handbook $^{17}$.

In the map of Figure 5, yellow indicates critical input documents to the capability management process; purple indicates important documents generated as outputs of the process; green indicates different MoD internal players involved in the process, and the blue oval indicates a terminology that is currently lacking an agreed definition: capability engineering. This lack leads to confusion and may lead to misunderstandings. The MoD acquisition operating Framework uses capability engineering synonymously with $\mathrm{TLCM}^{18}$, whereas within the defence research community, especially in The Technology Cooperation Program (TTCP), capability engineering concerns designing options, which synthesise all DLOD to meet requirements for a particular capability. It is the authors' judgement that the latter use of capability engineering is aligned with capability planning, which is depicted in Figure 6. TTCP $^{19}$ is a government to government organisation for information exchange in defence science and technology between Australia, Canada, New Zealand, United Kingdom, and United States.

The map in Figure 5 gives a glimpse of the complexity involved, especially when it is borne in mind that there are multiple CPGs and CMGs. Another complication, not shown in the diagram, is the existence of different budget lines. 


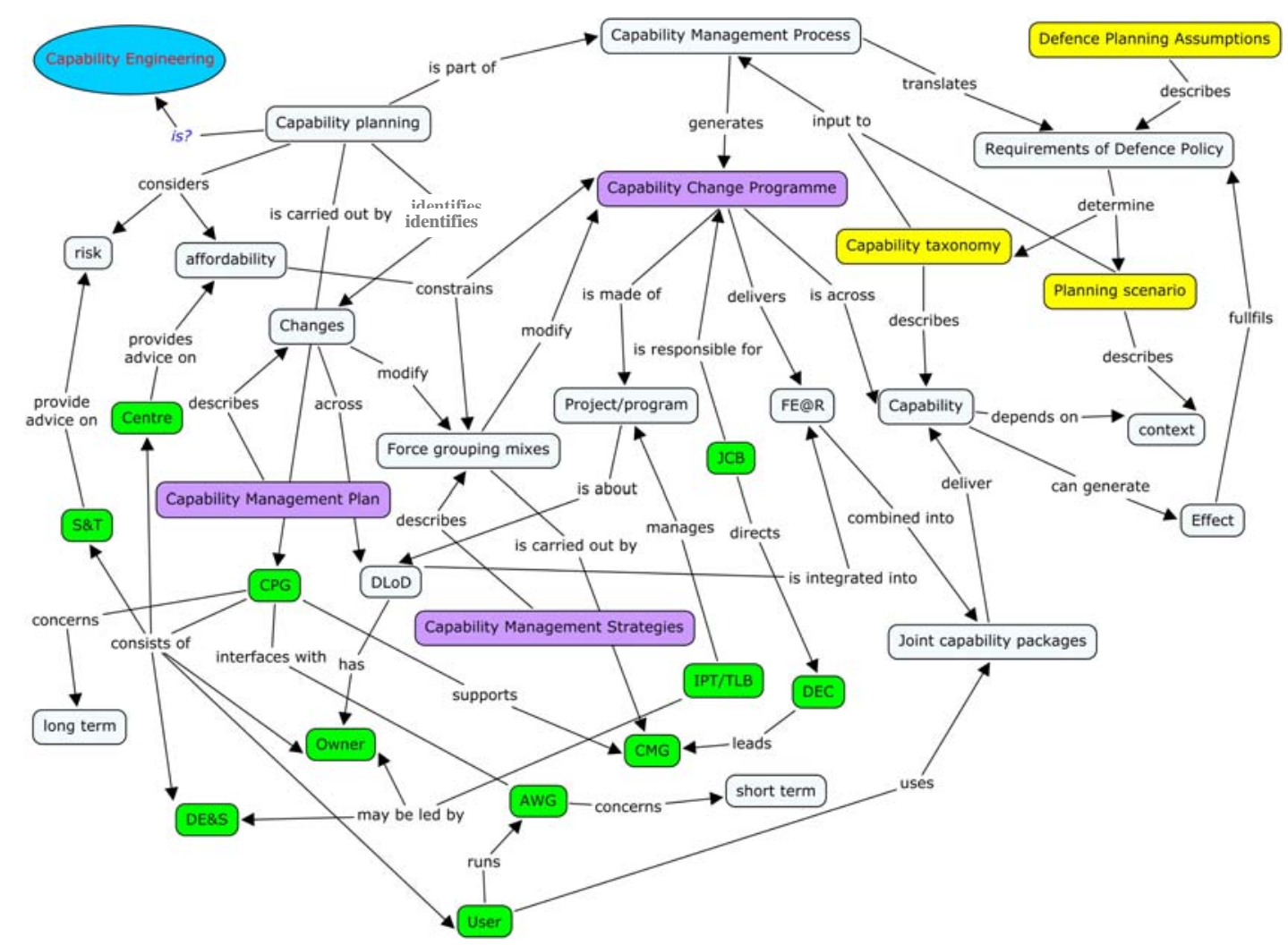

AWG = Availability Working Group;

$\mathrm{CMG}=$ Capability Management Group;

CPG = Capability Planning Group;

DEC = Directorate of Equipment Capability;

DE\&S = Defence Equipment and Support;

IPT = Integrated Project Team;

JCB = Joint Capabilities Board;

S\&T = Science and Technology Community;

TLB = Top Level Budget Holder;

Figure 5. A capability management concept map

One aspect of the planning, which is not obvious from the maps, is that it is iterative, and the output of the planning - capability change programme, is a rolling programme. However, one drawback of the process is that a learning mechanism is not explicitly built in. This is a crucial deficit where TLCM is concerned as effective learning has a significant impact on affordability.

A critical factor which will determine whether the planning is successful is how to measure a military capability. If wrong measures are adopted, no matter how robust the process is, the end result will still be disastrous. However, measuring capability is very difficult and our current knowledge in this area is dreadfully limited.

There is no doubt that military capability planning processes are knowledge intensive, hence a knowledge management perspective will definitely be helpful in the implementation and improvement of them. A shared mental model and common language will be a good starting point. The concept maps presented in this paper can 
be used to communicate the complex ideas in the domain and assist meaningful debate and discussions.

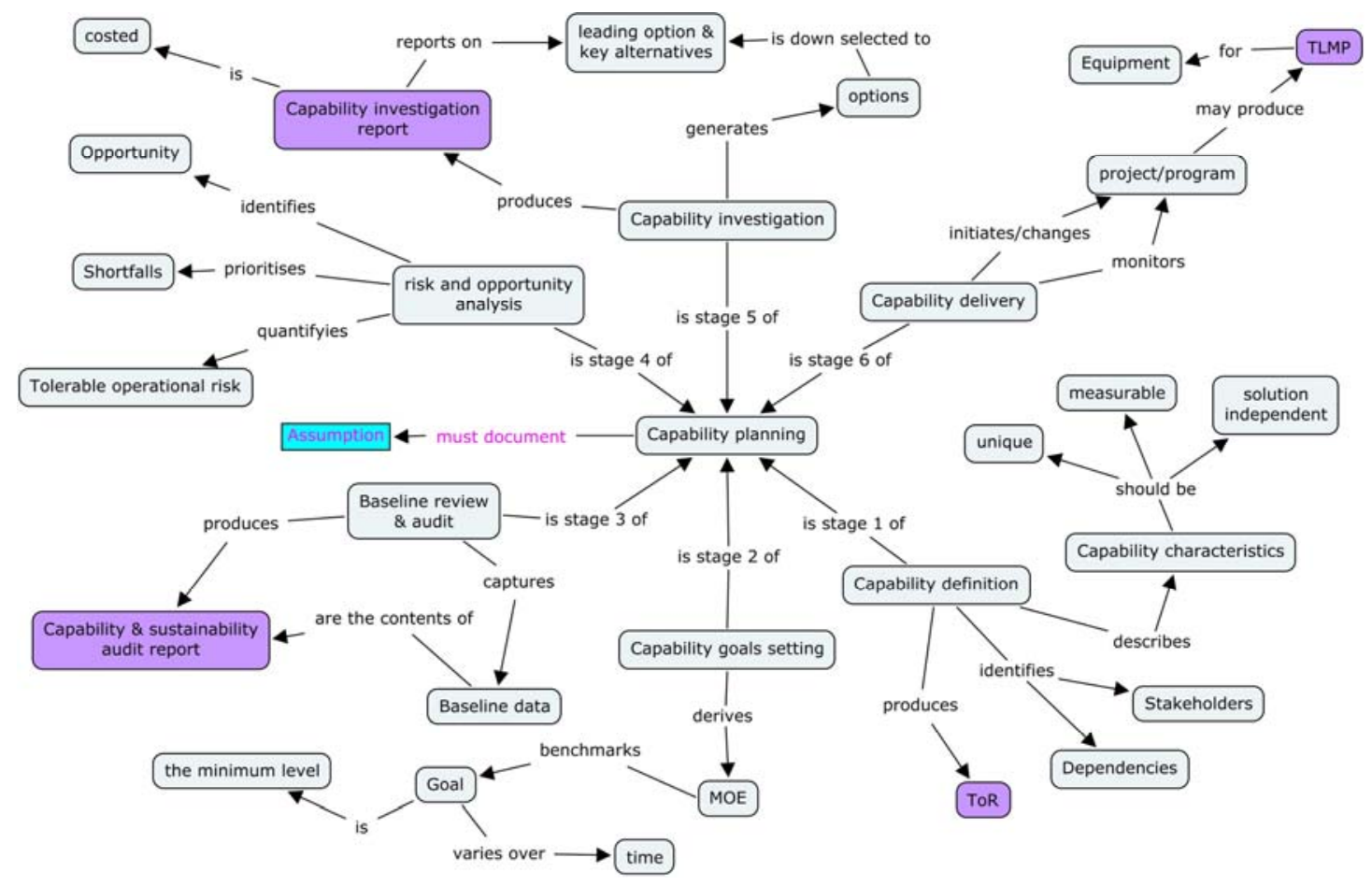

Figure 6. A concept map for the 6-stage capability planning process

The level of industrial involvement is not well defined in the process. It has been suggested (e.g. Daw $^{20}$ ) that industry is a ninth line of development. Industry capability is an important consideration for maintaining sovereign skills and abilities, but for planning purposes, it is probably more important to understand the role of industry in supporting DLOD for any particular capability and the alignment/relationship between supplier and customer in developing the DLOD.

The 6-stage process shown in Figure 6 addressed planning at the individual capability level. On top of this (at the JCB level) strategic balance of investment decisions must be made in a financially constrained environment, as shown in Figure 5. When evaluating options, the high uncertainty of the external environment means that flexibility and adaptability must enter this decision process with a higher weighting than has traditionally been the case. Partially reversible decisions will need to be considered and a portfolio management approach may have merit. A further change to the basis for decision making concerns the balance of efficiency and agility. The tightened budgetary environment will tend to promote the mantra lean and efficient, whereas solutions with greater opportunity to adapt in an agile fashion will likely provide the more cost effective approach over the long term. Research shows that when the resource and opportunities to explore for probable future benefits are removed, the system dies ${ }^{21}$. This is to say that systems that cannot readily adapt to a changing environment do not survive. 


\section{Summary}

Through Life Capability Management (TLCM) is the key theme of recent UK government defence policy documents, but the implications of this are not yet fully understood. This is, at least partly, because of different understandings of important concepts within the community. We emphasise here that capability must be considered at different levels and is fractal in nature. TLCM and the realisation of NEC cannot be considered independently, in fact they are intrinsically linked, and effective realisation is only possible if an holistic view is taken of UK military capability development. Such a view is attempted in this paper and we have described this approach as capability engineering; a term that is increasingly being used to express the System of Systems considerations necessary to manage capability over very long timescales. The fractal nature of capability, we suggest, clarifies the meaning of capability engineering as being concerned with the engineering of capabilities, whereas engineering with capabilities can be described as capabilitybased planning.

We have also noted that a lack of clarity about the meaning of the NEC concept has had a detrimental effect on its realisation, but this is likely to be addressed through a focus on capability, rather than on the network, as the system of interest.

Through the development of concept maps for TLCM and the recognised capability development process, and through a consideration of the stakeholders, we have extracted some important principles for TLCM and also identified some stumbling blocks that must be overcome if TLCM is truly to be realised. These effectively set a research agenda.

Affordability is the motivation for TLCM but whole-life costing is still a very significant challenge and, furthermore, affordability demands much greater sharing of information within the defence enterprise. This will require a significant change to the commercial arrangements for defence procurement, as well as the development of trusted models for whole life costing.

The role of industry as a contributor across all eight defence lines of development has been acknowledged explicitly in various government documents, but our capability management concept map (Figure 5) reveals that the structures are not yet in place to benefit from industry's participation. The six-stage capability planning process (Figure 6) does not have a learning mechanism explicitly built in, and this is of major concern because TLCM will rely on effective knowledge management. Agility and adaptability criteria must be given a higher priority at both the individual capability level and overall decision making in generating the capability change programme. Research is needed into planning and designing for adaptability in military capability. Finally, there is a clear need for the development of appropriate metrics for TLCM.

TLCM requires significant changes in the roles of UK MoD and industry and in the approaches that are taken in the planning, development and management of military capability. Through an holistic view of UK military capability development we have identified some of the challenges, and the concept maps presented above will be useful for understanding the nature of the changes needed to address them. 


\section{Acknowledgements}

Dr. Yue would like to thank DSTO for providing Defence Science Fellowship, Dstl for hosting her visit, and Dr Ben Taylor for many beneficial and stimulating discussions about TLCM and advice on this manuscript. Prof. Henshaw acknowledges the financial support of the EPSRC and BAE Systems through the NECTISE programme.

\section{References}

${ }^{1}$ UK Ministry of Defence. Defence Industrial Strategy - Defence White Paper Cmd 6697, 2005

${ }^{2}$ UK Ministry of Defence, The Director CBM / J6, JSP 777 - Network Enabled Capability, 2005

${ }^{3}$ UK Ministry of Defence, T. McKane. Enabling Acquisition Change: An examination of the Ministry of Defence's ability to undertake Through Life Capability Management, 2006

${ }^{4}$ N. N. Taleb, The Black Swan; the impact of the highly improbable, Penguin Books, 2007

${ }^{5}$ UK Ministry of Defence, TLCM Workstrand, Capability Management Handbook (Interim Edition), 2007.

${ }^{6}$ UK National Audit Office, Comptroller and Auditor General, Building an air manoeuvre capability: the introduction of the Apache helicopter, HC 1246 session 2001-2002, Oct. 2002.

${ }^{7}$ A. Daw, On the Onion of Integration, keynote presentation to International conference on innovation and integration in aerospace sciences, Queen’s University Belfast, 2005.

${ }^{8}$ UK Ministry of Defence, The JCB NEC Delivery Strategy, 2005

${ }^{9}$ Blair, C.D., Boardman, J.T., and Sauser, B.J., Communicating strategic intent with systemigrams: application to the Network Enabled Challenge, Systems Engineering, 10(4),pg. 273, Sept. 2007

${ }^{10}$ Quintana E. Is NEC dead? An analysis of industry's perspective on the UK's NEC programme, RUSI, 2007.

${ }^{11}$ UK MoD, Capability Management Handbook (Interim Edition), 2007.

${ }^{12}$ UK MoD, Acquisition Operating Framework, Nov. 2008.

${ }^{13}$ J.M. Early, J. Wang, R. Curran, M. Price, and S. Raghunathan, Dynamic Feedback Models for Whole Life Cost Prediction, $7^{\text {th }}$ AIAA Aviation, Technology, Integration and Operations Conf., Belfast. AIAA 2007-7706, Sept. 2007.

${ }^{14}$ D De Laurentis, C. Dickerson, M. DiMario, P. Gartz, M. Jamshidi, S. Nahavandi, A. Sage, E. Sloane, D. Walker, A Case for an International Consortium on System-of-Systems Engineering, IEEE Systems Journal, 2007. pp 68-73.

${ }^{15}$ B. Taylor, Capability based planning and capability engineering: where's the join? In IET Forum on Capability Engineering - At Home and Abroad, (2006/11589), pp. 53 -59, London, UK, 7 Nov. 2006

${ }^{16}$ W. R. Ashby, Principles of the self-organizing system, in H. V. Foerster \& J. G. W. Zopf (Eds.), Principles of self-organization: transactions of the University of Illinois symposium London: Pergamon Press 1962, pp. 255-278.

${ }^{17}$ UK MoD, Capability Management Handbook (Interim Edition), 2007. 
${ }^{18}$ UK Ministry of Defence, DE\&S, The Systems Engineering Handbook: Principles, Practices and Techniques, Mar 2007.

${ }^{19}$ http://www.dtic.mil/ttcp/

${ }^{20}$ A. Daw, On the Onion of Integration

${ }^{21}$ P. Allen Complexity, Evolution and Learning in Organizations and Supply Chains, presentation given at the Complex Adaptive Systems Workshop Dstl Farnborough Feb 2008. 